\title{
"Letraca", un proyecto de Educación Artística y refuerzo del aprendizaje de la lectura y escritura
}

Cristina Glez. Temprano cgtemprano@gmail.com

Independent researcher and educator, España

\section{Reference}

\section{Resumen}

Palabras clave

Abstract

Keywords
Temprano, Critina Glez; (2012) "“Letraca”, un proyecto de Educación Artística y refuerzo del aprendizaje de la lectura y escritura", p. 305-310. In: Barbosa, Helena; Quental, Joana [Eds]. Proceedings of the 2nd International Conference of Art, Illustration and Visual Culture in Infant and Primary Education. São Paulo: Blucher, 2015. ISSN 2318-695X, ISBN: 978-989-98185-0-7 DOI 10.5151/edupro-aivcipe-58

Educación artística, estimulación del hábito lector, apoyo en el aprendizaje de la lectura y escritura, y propiciación del interés por aprender, resumen el carácter y la particularidad de este proyecto. "Letraca" es un programa de intervención educativa en la escuela, efectuado por una educadora independiente, con el respaldo del centro escolar. Su programa de actividades persigue apoyar de forma directa el aprendizaje de la lectura y escritura, y por tanto, la expresión oral y escrita. Este objetivo concreto se logra actuando de una manera global en la educación del niño, puesto que la metodología educativa que investiga "Letraca" pretende actuar en su desarrollo integral, abarcando la dimensión física, emocional y cognitiva a través de actividades artísticas que propician tanto el aprendizaje como el descubrimiento de capacidades y habilidades. "Letraca" es un proyecto de educación artística cuyo objetivo es constituirse en un agente de actuación dentro de la mejora de la calidad educativa.

Educación artística, lectura, escritura, metodología, intervención

Artistic education, reading habit stimulation, reading and writing learning support, and the enhancement of interest for learning in general, can summarize the character and particularity that this project has. "Letraca" is a programme of educational intervention at school, that is led by an independent teacher with the backing of a scholar centre. Its programme of activities aims supporting directly the reading and writing apprenticeship, and therefore, the oral and writing expression. This specific objective is attained performing on the child's education in a global way. Since the educative methodology that "Letraca" is researching, tries to act in their integral development: involving physical, emotional and cognitive dimensions through the artistic activities; promoting the apprenticeship and the discovering of different capacities and skills. "Letraca" is a project of artistic education whose objective is to become an agent of acting within the improvement of educative quality

Arts education, reading, writing, methodology, intervention
Introducción

"Letraca" contribuye a despertar y desarrollar la creatividad a través de diferentes lenguajes artísticos y estimula al niño hacia el interés por aprender, refuerza su autoestima y además, desde el trabajo en grupo y la interacción constante con sus compañeros de taller, adquiere hábitos positivos de convivencia y respeto.

El programa de trabajo tiene la expresión plástica como eje, pero la relaciona con otras disciplinas: juegos teatrales, expresión corporal, música, y expresión oral. Los cuentos, y en especial el álbum ilustrado, están presentes de manera constante. Con ellos, además de acercar 
al niño a la lectura, al lenguaje y a la ilustración, se contribuye al desarollo de su inteligencia emocional.

La intervención educativa del proyecto "Letraca" se apoya en: las investigaciones que avalan la importancia y el valor de las artes tanto en la adquisición de aprendizajes, como en la maduración emocional de la persona; en las aportaciones de la neuropsicología y la psicología cognitiva para afrontar las dificultades del aprendizaje; y en experiencias y estudios de educación artística que estímulan activamente la creatividad del niño. Sobre estas bases, el proyecto elabora una cuiada programación con actividades que interaccionan entre sí, entrelazando diferentes lenguajes artíticos. Este método de trabajo, ofrece al niño una rica gama de estímulos, activando sus capacidades de aprendizaje y mejorando su rendimiento escolar. Esta esperada repercusión en el desarrollo del niño, será el resultado de haberle procurado, en las sesiones de educación artística, una vivencia sugerente, un contacto atractivo con el aprendizaje, conviertiendo al niño en protagonista de actividades que hayan reforzado su autoestima, y hayan despertado su interés por aprender, investigar, experimentar, por esforzarse, por hacerse preguntas, resolver enigmas, etc.; en suma, el programa logrará ser efectivo si los niños alcanzan la consecución de los objetivos artístico-educativos programados, a través de vivencias de alegría y disfrute en relación al aprendizaje, los compañeros y la escuela.

En la primera fase de la investigación, "Letraca" se ha desarrollado actuando sobre diferentes grupos de niños, a través de un numero de sesiones que ha variado entre 4 a 15 a lo largo del curso, durante dos cursos escolares, en los niveles de $1^{\circ}$ y $2^{\circ}$ de Primaria e Infantil de 5 años. Las sesiones se han llevado a cabo en el horario escolar, con la presencia de las tutoras de los grupos. La reacción de los niños ante el taller ha sido siempre muy buena, demostrando abiertamente entusiasmo y una disposición abierta y activa hacia todas las sesiones. Estos buenos resultados en las actitudes de los niños, y el apoyo y la valoración de los maestros que han participado en él, me impulsan a abordar la siguiente fase de la investigación, que consistirá en, por una parte, ampliar su tiempo de ejecución, creando planes que permitan intervenciones intensivas, y por otra, involucrar a la familia, tutora, y orientadora del centro, para implicar a todos los agentes que actúan en la educación del niño, y poder realizar una evaluación lo más certera posible, del impacto del proyecto en el devenir escolar.

Al término de la investigación, se podrá establecer un método novedoso y riguroso de intervención en la escuela a través de la educación artística, que quedará plasmado tanto en material didáctico creado a partir de la experiencia y su análisis, como en la exposición y elaboración de las conclusiones de la investigación.

"Letraca" es un proyecto de educación artística que puede constituirse en un agente de actuación dentro de la mejora de la calidad educativa.

\section{Palabras y artes: lectura, escritura, libros y creatividad}

Estos son los ingredientes de nuestra receta. Relacionar la palabra con experiencias artísticas, relacionar la lectura y la escritura con las artes, la exploración de la creatividad con los libros. "Letraca" nace como la evolución lógica de un proceso vital y laboral, y aúna mis inquietudes personales y especialidades profesionales. Comencé a investigar y trabajar la educación artística en 1999, desarrollando esta actividaden diferentes ámbitos como programas de implantación del arte en las escuelas, centros culturales, bibliotecas, actividades extraescolares, escuelas de verano, o centros de menores, entre otros. Desde el principio, y durante todos estos años, he reflexionado sobre, empleando las palabras de Arnheim, " Qué hace el hombre para crear arte y qué hace el arte para crear seres humanos". (Arnheim,1993).

Buscando respuesta a esta pregunta y convencida de los efectos beneficiosos de la actividad artística en el proceso de formación de la persona, he recorrido mi camino como educadora convencida de la utilidad del arte para propiciar experiencias de percepción, observación, coordinación, aceptación, comprensión, cooperación, atención, expresión, exploración, relajación, toma de decisiones, asunción de riesgos, etc., experiencias que nos permiten crear, aprender, y desarrollar la sensibilidad. Los beneficios del arte se dejan notar tanto en el desarrollo del individuo, como en su relación con los demás, siempre y cuando, la vivencia haya estimulado verdaderamente tanto nuestros sentidos como nuestra creatividad y nuestro 
2nd International Conference Art, Illustration and Visual Culture in Infant and Primary Education $2^{\circ}$ Congreso Internaciona

Arte, llustración y Cultura Visual en Educación Infantil y Primaria
'Congresso Internaciona

de Arte, Ilustração e Cultura Visual

na Educação Infantil e Primária

pensamiento, algo que no siempre se consigue ni en la escuela, ni en determinados centros de educación artística, que circunscriben dicha formación a la repetición de modelos, sin ocuparse de fomentar un espíritu crítico, abierto, libre y creativo. Son muchos los autores que han puesto de manifiesto la deficiente educación artística que encontramos en muchos ámbitos de nuestra sociedad, uno de ellos es Carmen Díaz Jiménez quien asegura que para evitar el actual fracaso escolar es necesario un cambio radical en los planteamientos educativos, sustituyendo el mimetismo y la memoria por la riqueza que supone la creatividad, es decir, optar decididamente por los valores del pensamiento divergente en lugar de los del pensamiento convergente. Más allá de la formación individual, la educación debería promover el trabajo en grupo, la cohesión grupal, la convivencia, la tolerancia, debería contribuir a la formación de una sociedad más justa compuesta por una ciudadanía participativa, un reto educativo que también puede abordarse contando con el arte. Como dijo el músico Y. Menuhin en algunas de sus intervenciones públicas,"La música y las artes invitan a la participación y constituyen un antídoto contra los obstáculos a la armonía entre los hombres". Por su parte, Díaz asegura que:

\section{El pensamiento divergente ayuda a formar actitudes de apertura y compresión, lo cual favorecerá que superemos barreras ideológicas que entorpecen las relaciones humanas. Una mente dúctil, es capaz de superar los condicionamientos que imponen los sistemas, permitiendo un mayor desarrollo} de calidad humana. (Díaz, 1986).

Estoy plenamente convencida de que la educación a través del arte, es una alternativa idónea para afrontar los retos que plantea la escuela, el sistema educativo y la sociedad en el momento actual, compartiendo el enfoque de Arnheim que propone una visión del arte y de la mente que sitúa al arte (su percepción y su creación) en el corazón del proceso educativo.

Al mismo tiempo que avanzaba en mi labor como educadora, seguía mi camino artístico atendiendo a dos inquietudes: el mundo plástico y visual, y la narración oral. Después de diez años contando cuentos e investigando la animación lectora, decidí imbricar absolutamente mis caminos artísticos y profesionales, en la creación de un método de educación artística, que conjugue la educación a traves del arte; los cuentos, la lectura, la narración y creación de historias; desde una perspectiva científica, dentro de la cual los avances en neuropsicología vendrían a demostrar los efectos de la práctica artística en el desarrollo del cérebro.

El valor de la narración, la educación de la escucha, el gusto por la palabra, la expresión oral, la animacion de los hábitos lectores, necesita de una constancia y una regularidad para dejar huella palpable en el proceso escolar de un niño, como dice Montserrat del Amo "(...)El niño necesita un impulso inicial que le conduzca hasta los libros, y una asistencia que, durante cierto tiempo, dirija su atención hacia ellos". (del Amo, 2004). Por eso en "Letraca" los cuentos están presentes cada día. Junto a ellos los niños se acercan a la belleza de las palabras, del lenguaje, de las historias; se dejan llevar por la imaginación, ven reflejados sus sentimientos o se identifican con lo que le sucede a los personajes. A través de los cuentos se asoman al mundo y disfrutan aprendiendo.

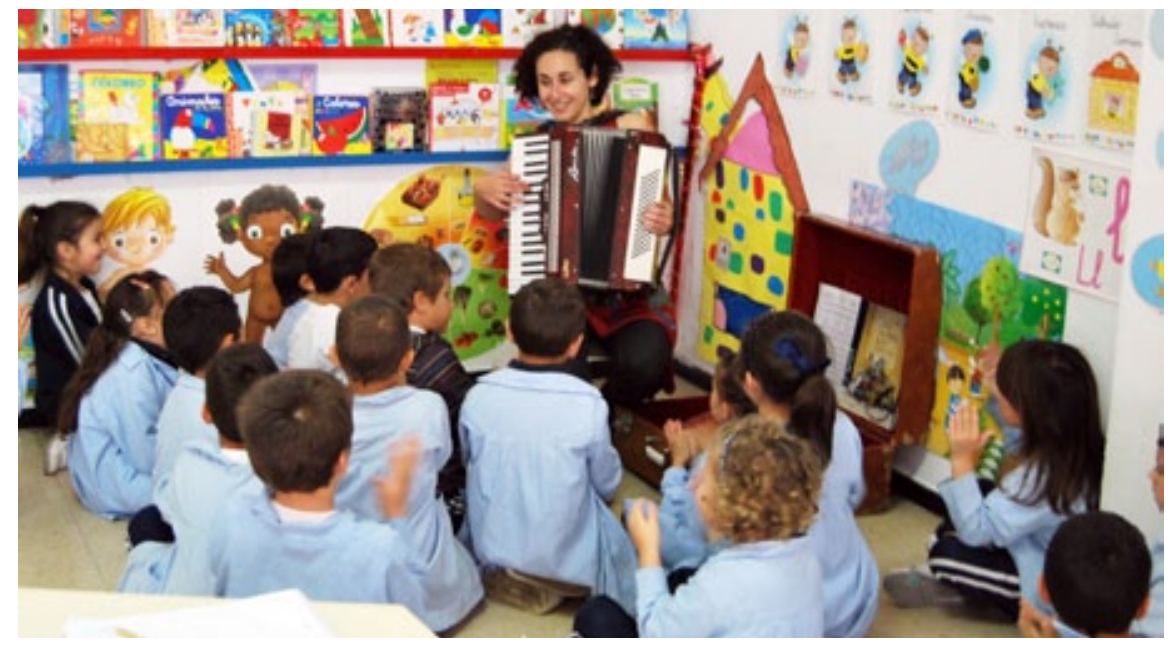

Figura 1. Sesión artística "Letraca". Contando un cuento con música de acordeón, y juegos de ritmos con las palmas (28 de marzo de 2012). Colegio Virgen de los Volcanes, Lanzarote, España. Fuente: propia. 
2nd International Conference Art, Illustration and Visual Culture in Infant and Primary Education $2^{\circ}$ Congreso Internacional

Arte, llustración y Cultura Visual en Educación Infantil y Primaria
Arte, llustraçáno e Cultur

de Arte, llustração e Cultura Visual

na Educação Infantil e Primária

El éxito de los cuentos a cualquier edad reside en la fuerza con la que llegan a lo más profundo. Funciona cuando se consigue conectar en su metáfora con la existencia actual de quien lo recibe. (...) Una historia nos atrae si sus imágenes interiores han resultado agradables, divertidas, sugerentes, reconocibles. La sentimos como propia porque lo que sienten y viven los personajes nos recuerda sentimientos y vivencias muy cercanas. Nos atrapa su argumento porque seguramente se acerca a los temas vitales ya superados o que estamos desarrollando en el momento del hallazgo. (Ortiz, 1986)

Más allá de que el niño se aficione a la lectura, o de los beneficios que pueda obtener de ella, hay una realidad escolar que debemos atender: el nivel de lectura de los niños es cada vez más bajo, en especial la lectura comprensiva, así lo revelan tanto estudios recientes, como las maestras. Y la afición a los libros no resulta nada fácil de inculcar... Sin embargo, la lectura será fundamental para el éxito escolar de los niños. Es crucial por tanto que aprendan a leer bien, que aprendan a comprender lo que leen, resultará más fácil y atractivo el colégio si logran esta tarea cuanto antes, y aún será mejor si aprenden disfrutando.

Para lograr efectividad en el apoyo del aprendizaje de la lectura y la escritura, planteo un programa de actividades que no resulte en absoluto una prolongación de la rutina escolar sino que actúe como elemento motivador, estimulante, divertido.

(...) Nuestra experiencia clínica nos permite afirmar que más del 50\% de los niños que fracasan en la escuela es porque han iniciado sus aprendizajes escolares sin haber desarrollado correctamente un orden corporal, el control de su movimiento, un conocimiento del espacio, una motricidad precisa o una correcta función visual o auditiva o una correcta lateralización, imprescindibles para aprender disfrutando. (Ferré, 2002).

Las experiencias prácticas de evaluación neuropsicológica aseguran que en adquisición del aprendizaje de la lectura y la escritura será indispensable un buen desarrollo de la coordinación motriz, de la lateralidad, del sentido del ritmo, de la discriminación auditiva, del tacto, y de la destreza manual. "Letraca" incide en todos estos aspectos, a través de las artes, utilizando creación plástica, educación visual, juegos teatrales, expresión corporal, música, invención de historias, y expresión oral, trazando un camino que lleve de manera natural de una a otra forma de expresion artística, un camino que permita a los niños ampliar su campo de percepción, su sensibilidad, su capacidad de respuesta ante los estimulos y su capacidad creadora. Para Arnheim, el sistema sensorial es uno de los principales recursos para el completo desarrollo de nuestra vida cognitiva, y defiende la idea de que la visión es una función de la inteligencia, que la percepción es un suceso cognitivo, que interpretación y significado son un aspecto indivisible de la visión y que el proceso educativo puede frustrar o potenciar estas habilidades. Este autor defiende la influencia de la enseñanza y la práctica del arte en el desarrollo de la mente, sus teorías sostienen que la percepción y la creación del arte visual son los agentes primarios en el desarrollo de la mente.
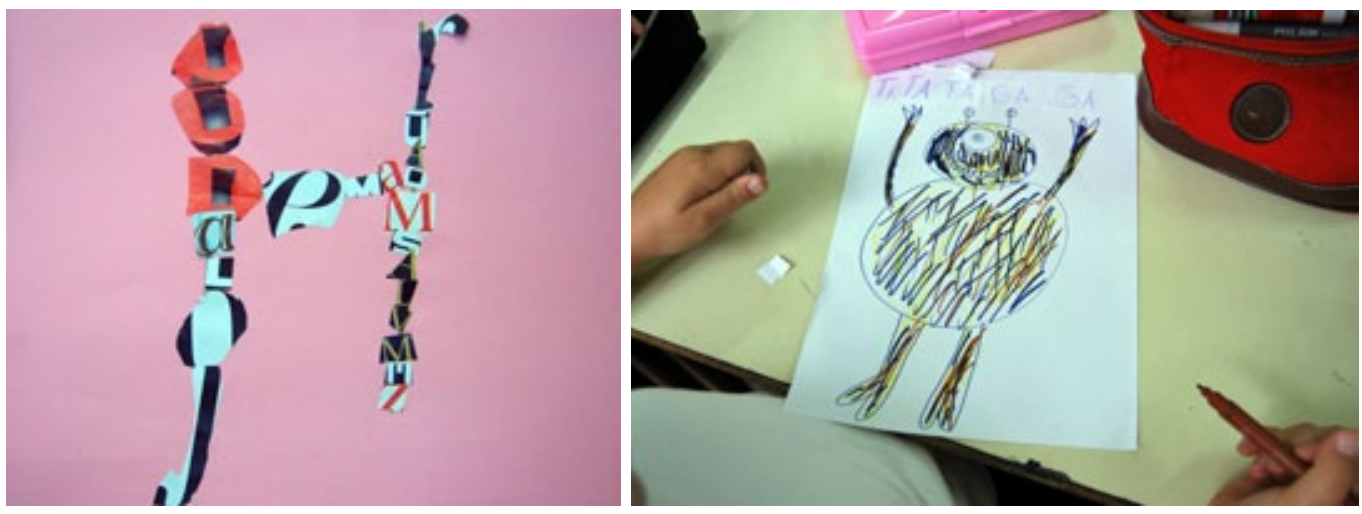

Figuras 2 y 3. A la izquierda: Collage de Hary (6 años), "Un diseño de letra con letras" (26 de noviembre de 2009). Colegio Nieves Toledo, Lanzarote, España. Fuente: propia. A la derecha: Trabajo de taller. Acoidán (7 años) Inventando un monstruo, su aspecto y sus cualidades monstruosas, a partir de un juego de palabras y un cuento narrado previamente (28 de marzo de 2012). Colegio Virgen de los Volcanes, Lanzarote, España. Fuente: propia.

En definitiva, "Letraca" pretende motivar y estimular al niño para que logre superar sus dificultades con la lectura y la escritura y quiere ser un agente efectivo de animación lectora, procurando que los niños se interesen por la lectura y la escritura y se sientan motivados en su aprendizaje, actuando tanto en la prevención como en el tratamiento de las dificultades del aprendizaje y como refuerzo al trabajo escolar. 
$2^{\text {nd }}$ International Conference Art, Illustration and Visual Culture in Infant and Primary Education $2^{\circ}$ Congreso Internaciona

Arte, Ilustración y Cultura Visual en Educación Infantil y Primaria
' Congresso Internacional

de Arte, Ilustração e Cultura Visual

na Educação Infantil e Primária

\section{1. Educación artística y competencial}

\subsection{Tendiendo puentes:} Escuela-familia-educación.

\section{Conclusión}

\section{Referencias bibliográficas}

Díaz J., C. (1986). La creatividad en la expresión plástica. Propuestas didácticas y metodológicas. Madrid: Narcea S.A.

Arnheim R. (1993). Consideraciones sobre la educación artística, Barcelona: Paidós.

Amo del M. (2004) La hora del cuento. Alicante: Biblioteca Virtual Miguel de Cervantes.

Ortiz E. (2002) Contar con los cuentos. Guadalajara: Palabras del candil (2009)

Antiuste, V. y Beltrán, J. (coord.), (1998). Dificultades de aprendizaje. Madrid: Síntesis.

Jensen, E., (2004). Cerebro y aprendizaje. Competencias e implicaciones educativas. Madrid: Narcea.
Y si el objetivo último de Letraca es favorecer el aprendizaje, su objetivo primero es ofrecer al niño un programa de educación artística creado por una artista-educadora que complete enación general. Es también elaborar un método de educación artística en relación al importancia de la educación artítica en la escuela.

Partiendo de la base de que la creatividad se puede estimular, tanto la del niño, como la del maestro, con esta experiencia quiero ofrecer herramientas útiles para el docente, aplicables en su práctica diaria, que le permitan renovar sus planteamientos y encontrar en el arte un aliado, y

Con esta investigación abordaré la educación por competencias desde el arte, señalando la educación artística como un eje vertebrador de un enfoque competencial de la enseñanza.

Como he mencionado en la introducción, hasta ahora "Letraca" se ha desarrollado en el entorno orientadores en el desarrollo de los talleres. De este modo, además de favorecer las relaciones cor en como la evaluación de los resultados, cuente con la participación del colegio, pues este es el horário no lectivo y en grupos reducidos. Una vez conocidas las particularidades de cada niño, se elabora una programación general, que se adaptará después en función del desarrollo de los talleres, para procurar un enfoque construccionista, y una atención personalizada a cada caso.

A nivel general, esta investigación propone soluciones originales y recursos que ayuden a renovar la concepción y uso de la educación artística en la escuela, pudiendo contribuir a la formación de la comunidad educativa, respondiendo así a la necesidad de emplear nuevos enfoques que permitan una mejora de la calidad educativa.

"Letraca" interviene en un momento clave, crucial para los niños: el momento en que aprenden leer. De cómo se produzca esta experiencia, dependerá en buena medida, tanto el desarrollo

Al término de la investigación, se podrá establecer un método novedoso y riguroso de intervención en la escuela a través de la educación artística, que quedará plasmado tanto en material didáctico creado a partir de la experiencia y su análisis, como en la exposición y elaboración de las conclusiones de la investigación. Asímismo, programaré intervenciones intensivas, de tres meses de duración, esta vez en 
2nd International Conference Art, Illustration and Visual Culture in Infant and Primary Education $2^{\circ}$ Congreso Internacional Arte, Ilustración y Cultura Visual en Educación Infantil y Primaria
Congresso Internacional

de Arte, llustração e Cultura Visual na Educação Infantil e Primária

Gómez-Tolón, J., (1997) Rehabilitación psicomotriz en los trastornos de aprendizaje. Zaragoza: Mira Editores.

Martín Lobo Ma P., (2003) La lectura. Procesos neuropsicológicos del aprendizaje, diagnósticos, estudios de casos y programas de intervención. Barcelona: Lebón.

Levitin, D.J., (2006) Tu cerebro y la música. Traducción al castellano por José Manuel Álvarez. Barcelona: RBA Libros, S.A. (2008). 